\title{
Novas formas organizacionais - a necessidade de superação das perspectivas sobressocializadas e subsocializadas
}

\author{
Mariana Baldi*
}

\section{Resumo}

Este trabalho tem como pressuposto que a análise de novas formas organizacionais deve superar tanto perspectivas sobressocializadas quanto perspectivas subsocializadas. Isso quer dizer que é necessário superar, respectivamente, os estudos que reduzem a explicação de formas organizacionais a aspectos de origem puramente cultural, como também aqueles que reduzem sua explicação a aspectos puramente econômicos ou de mercado.

As formas organizacionais sociais e econômicas apresentam, simultaneamente, uma dependência e uma autonomia em relação aos quadros cultural e institucional de cada país, estando imbricadas nesses quadros. Numa perspectiva contextualizada, múltiplas identidades se tornam possíveis, as quais não são necessariamente oriundas de uma cultura dominante. De acordo com Clegg (1998), o objeto de análise não deve ser necessariamente as organizações em si, mas os processos e mecanismos que permitem a organização e a desorganização. É proposta a perspectiva do embeddedness como um referencial de análise que supera os limites das abordagens comumente utilizadas para identificar e compreender as novas formas organizacionais.

0 conceito de embeddedness e seus mecanismos permitem trazer à tona várias narrativas (cultural, política, estrutural e cognitiva), e através delas se compreende como as organizações são formadas e mudadas, possibilitando enfocar questões por uma ótica ainda pouco trabalhada nos estudos organizacionais.

Palavras-chave: novas formas organizacionais; abordagem contextualizada; embeddedness.

\begin{abstract}
This paper considers that an analysis about new organizational forms must overcome both subsocialized and under socialized perspectives. It means that it's necessary to overcome respectively the studies that understand the organizational forms merely as a cultural issue and the studies which usually focus their analysis strictly on the economic aspects or on the market forces.

Both social and economic organizational forms are at the same time dependent and independent on the cultural and institutional context in the different countries. Thus, they are embeddedness in this framework, and in this sense, multiple identities are something possible but not necessarily derived from a dominant culture. According to Clegg (1990), the process and mechanisms that allow organization and the disorganization must be the theoretical object of analysis, not necessarily the organization per se. This study proposes the concept of embeddedness as an analysis framework that can overcome limits of the approaches usually adopted to identify and understand new organizational forms.

The concept of embeddedness and its mechanisms allows evincing different narratives (cultural, political, structural, and cognitive). These narratives allow us to understand the way organizations are arranged and how they change, in the sense they focus on different questions in a so uncommon perspective in terms of organizations studies.
\end{abstract}

Keywords: new organizational forms; contextualized approach; embeddedness.

* Doutoranda em Administração pela Escola de Administração da Universidade do Rio Grande do Sul. Mestre em Administração pela Universidade Federal de Santa Catarina.

Artigo recebido em dezembro de 2003 e aceito em fevereiro de 2004. 


\section{Introdução}

Atualmente, existe a premissa de que a globalização e a busca por novos mercados intensificaram a competitividade, gerando a necessidade de se redesenhar estruturas organizacionais e modos de produção. A flexibilidade passa a ser encarada como necessária para fazer frente à customização da economia, que exige maior agilidade produtiva. Dessa forma, as organizações não poderiam sobreviver com estruturas burocráticas, diante da pressão pela redução de seus níveis hierárquicos e pela descentralização do processo de tomada de decisão. Esses aspectos indicariam a superação da diferenciação que caracteriza a sociedade moderna. Em outras palavras, estaria ocorrendo a transição das formas burocráticas para as formas organizacionais pósburocráticas, também denominadas novas formas organizacionais (THOMPSON, 1993; CLEGG, 1998; HEYDEBRAND, 1989).

A discussão sobre novas formas organizacionais vem sendo mantida sem estar baseada num referencial teórico mais sólido. Por isso, Dellagnelo (2000) afirma que o seu aprofundamento é de fundamental relevância teórica e empírica, tanto pela importância para os estudos organizacionais sobre a constatação ou não de rupturas no projeto modernista, como pelo fato de existirem poucos casos analisados na realidade brasileira.

É importante esclarecer o conceito de "novas formas organizacionais", pois na sociedade moderna tornou-se comum a assimilação e a apropriação de conceitos sem uma reflexão sobre os mesmos (RAMOS, 1989). Nesse sentido, a sistematização das noções de modernidade e pós-modernidade, bem como do que sejam organizações burocráticas e novas formas organizacionais, é fundamental para o debate.

Compreender como o pensamento moderno e o capitalismo se associam a uma discussão epistemológica e ontológica da ciência é essencial para entender que a promulgação de características universais do modelo burocrático está atrelada ao projeto modernista. Este artigo discute o despertar do capitalismo, tendo em vista que o surgimento da teoria organizacional está intimamente relacionado a esse período.

Para Clegg (1998), a sociologia de Weber e o estudo sistemático das organizações apresentavam uma afinidade eletiva decorrente do pessimismo cultural do autor. Ou seja, o pressuposto era de que a "racionalização" do mundo conduziria a um "cativeiro no colete-de-forças" burocrático. Dessa forma, qualquer que fosse o caminho da modernidade, o elemento essencial e inevitável seriam as organizações associadas não a múltiplas formas, mas a uma forma específica.

É importante notar que "o colete-de-forças é uma construção cultural, e não um constrangimento racional" (CLEGG, 1998, p.67). Essa afirmação significa que a expansão da burocracia não ocorre exclusivamente pelo seu aspecto técnico de eficiência, mas pelas condições culturais.

A noção de totalidade - que marca o desenvolvimento do projeto moderno - é questionada pelas abordagens pós-modernas, que defendem não a existência de uma grande narrativa, mas a existência de múltiplas narrativas.

A discussão pós-moderna nos estudos organizacionais está baseada em duas perspectivas. A primeira está relacionada à forma de ver o mundo e a uma questão epistemológica. A segunda, de natureza ontológica, está atrelada a uma questão de periodização, ou seja, tem a preocupação de compreender uma sociedade que está se encaminhando para uma nova era (PARKER, 1992; THOMPSON, 1993; HASSARD, 1993).

A transformação da sociedade requer formas organizacionais diferentes daquelas que caracterizaram a modernidade. Enquanto a modernidade é marcada pela crescente divisão do trabalho ("diferenciação"), a pósmodernidade se caracteriza pelo decréscimo dessa diferenciação, ou como Clegg (1998) denomina, "desdiferenciação".

No que se refere à perspectiva de periodização, percebe-se uma corrente que parte do pressuposto da noção de tempo como algo linear e evolutivo, baseando-se ainda em pressupostos modernistas de ordem e progresso; enquanto uma outra corrente defende a noção de tempo como algo que não se esgota em si mesmo. Ou seja, como uma espiral que vivencia ao mesmo tempo diferentes realidades (BURRELL, 1979). Nessa linha de 
pensamento não está implícita a idéia de superação da modernidade, mas a preocupação em estabelecer uma distinção entre esta e a pós-modernidade, não considerando necessário o desaparecimento da primeira para que se observe evidências empíricas da segunda.

Este artigo defende a idéia de que, no sentido assinalado por Granovetter (1985), as perspectivas dominantes sobre forma organizacional são subssocializadas, ou seja, conceituam eficiência dissociada de seu contexto social, analisando as novas formas apenas como uma resposta às contingências ambientais. Exemplos disso são as abordagens centradas no mercado, ou as perspectivas que percebem o ambiente como fonte de incertezas e a organização como uma entidade delimitada, que busca fazer frente a esse contexto.

Este estudo também considera que analisar essas novas formas como oriundas unicamente de contextos culturais diferentes resulta de perspectivas tão reducionistas quanto as anteriores, por serem sobressocializadas, na definição de Granovetter (1985).

Assim, tal como Granovetter (1985), busca-se ressaltar a necessidade de uma perspectiva contextualizada da organização social da ação econômica. O entendimento é de que as formas organizacionais sociais e econômicas possuem uma dependência e uma autonomia relativas aos quadros culturais e institucionais de cada país, estando imbricadas nesses quadros.

Numa perspectiva contextualizada, é reconhecida a possibilidade de múltiplas identidades, as quais não são, necessariamente, oriundas de uma cultura dominante. Estas devem ser analisadas a partir dos "circuitos de poder", da perspectiva cultural e do contexto institucional. O entendimento é o de que os modos de racionalidade são construídos a partir dos recursos culturais, das formas de regulação institucional, e que são estabelecidos nos circuitos de poder (CLEGG, 1998).

\section{Os estudos organizacionais: modernismo e pós- modernismo}

A modernização, propiciada pelo capitalismo, foi permeada por mudanças nas diversas esferas da vida (econômicas, políticas e sociais), possibilitando o surgimento da chamada sociedade organizacional. Isso levou Clegg (1998, p.2) a afirmar que "a teoria organizacional é uma criação da modernidade".

É no período moderno que termos como "razão", "ciência" e "natureza" sofrem uma alteração no seu sentido semântico, cujo impacto pode ser observado no próprio desenvolvimento dos estudos organizacionais. Para Ramos (1989), a razão era entendida inicialmente como uma força da psique humana, que habilitava o indivíduo a diferenciar entre o bem e o mal, entre o conhecimento verdadeiro e o conhecimento falso, possibilitando a ordenação de sua vida pessoal e social.

A transformação do conceito de razão se verifica a partir da definição de Hobbes, perdendo, então, qualquer papel normativo. A razão passa a ser concebida como uma capacidade do indivíduo, adquirida pelo seu próprio esforço, transformando-se em sinônimo de cálculo utilitário de consequiências (RAMOS, 1989).

Quanto ao sentido da ciência, Horckeimer e Adorno (1985) identificam que Platão, em seus últimos escritos, equiparou as idéias aos números, tornando-se um cânon do Iluminismo. A lógica formal possibilitou uma uniformização, tornando comparável coisas que não têm denominador comum. Portanto, a lógica é a de que o que não pode ser reduzido a números, deve ser colocado no domínio da poesia.

Para Ramos (1989), a ciência social resulta dessa racionalização e a teoria organizacional existente se fundamenta numa ciência social com essa natureza epistemológica. É o projeto modernista, com seu arcabouço ideológico dominante que predomina nos estudos organizacionais, desde a sua origem até a metade/fim do século XIX (Reed, 1993).

A representatividade da sociedade organizacional residia no avanço da razão, da liberdade e da justiça, o que caracterizava a supremacia da ciência sobre a política, gerando ordem e progresso coletivos, expurgando a 
irracionalidade humana. Dessa forma, era defendida a idéia de que as organizações racionais resolveriam os conflitos entre as necessidades coletivas e as vontades individuais (REED, 1998).

A posição epistemológica do pensamento modernista reside na crença de que é o poder do pensamento racional que possibilita à humanidade se auto-aperfeiçoar, sendo esta a sua capacidade essencial. Nesse sentido, o modernismo pode ser caracterizado como o momento em que o homem inventou a si mesmo, não se percebendo mais como o reflexo da natureza ou de Deus (COOPER e BURRELL, 1988).

A humanidade parte de um mundo habitado pelo sagrado, pelo mágico e chega a um mundo racionalizado e material, manipulado pela técnica e pela ciência. Ocorre o chamado desencantamento do mundo. As primeiras metanarrativas nos estudos organizacionais eram centradas na ordem coletiva e na organização racional para $o$ alcance do progresso. "A criação de uma teoria é uma prática intelectual situada num dado contexto histórico, e que está voltada para a construção e mobilização de recursos ideais, materiais e institucionais para legitimar certos conhecimentos e os projetos políticos que dele derivam" (REED, 1998, p.64).

A epistemologia atrelada ao projeto modernista é caracterizada pelo positivismo, que, conforme Burrell e Morgan (1979), procura compreender e predizer o que acontece no mundo social, através da busca por "regularidades" e de uma análise "causal" de seus elementos constituintes. A epistemologia positivista é baseada, essencialmente, numa abordagem tradicional, a qual domina as ciências naturais, permitindo que sejam estabelecidas leis sociais, da mesma forma como nas ciências naturais. (CARTER e JACKSON, 1993; CÁlAS e SMIRCICH, 1999). A partir dessa concepção, características "universais" da realidade - e, conseqüentemente, das organizações - passam a ser promulgadas.

Durante muito tempo, os estudos organizacionais "viveram" uma fase de ciência normal, caracterizada por modelos teóricos amplamente aceitos e institucionalizados, através dos quais se procura resolver problemas e desenvolver programas de pesquisa, de maneira incremental (REED, 1999). Nesse período, os estudos organizacionais foram majoritariamente analisados a partir dos pressupostos funcionalistas, orientados basicamente pela sociologia da regulação, procurando compreender as condições de regularidade social. (BURREL e MORGAN, 1979).

O consenso e a identidade intelectual dos anos 1950 e 1960 passam a ser fortemente questionados nos anos 1980 e 1990. A natureza dos estudos organizacionais começou a demonstrar que se iniciava uma fase de ciência "revolucionária", caracterizada pela crítica e a reavaliação contínua dos pressupostos e dos modelos de interpretação que, até então, orientavam a análise organizacional (REED, 1999). Entretanto, a multiplicidade de paradigmas que passa a permear os estudos organizacionais ainda está centrada numa discussão modernista. Calás e Smircich (1999) afirmam que cada paradigma é uma metateoria em busca do conhecimento verdadeiro, cada um oferecendo um poder explicativo mais amplo sobre o mundo. As autoras salientam que o aparecimento dessa multiplicidade, por si só, não representa a mudança de uma discussão moderna para uma discussão pós-moderna, ainda que essa condição tenha antecipado o aparecimento de uma "teorização" pósmoderna.

Ainda que os pós-modernos rejeitem rótulos ou definições, o pós-modernismo tem sido caracterizado pela descontinuidade, pela fragmentação e a indeterminação (CLEGG e HARDY, 1998; PARKER, 1992). O termo tem sido utilizado num conjunto de abordagens filosóficas nas ciências sociais e em outras áreas, bem como para caracterizar um período histórico permeado por mudanças sociais e organizacionais (ALVESSON e DEETZ, 1998).

A ênfase na grande narrativa e na noção de totalidade é invertida pelas abordagens pós-modernas, as quais supõem que "nenhuma grande narrativa marca o desenvolvimento das histórias humanas. São histórias e nãohistória: deve-se atentar para o local, para as especificidades fragmentadas, para as narrativas das vidas diárias" (CLEGG e HARDY, 1998, p.29).

Como já foi dito anteriormente, o modernismo tem suas raízes no pensamento iluminista e, portanto, na concepção de que, através da razão, o homem é capaz de levar a humanidade ao progresso. Assim, muito 
embora existam várias versões divergentes do modernismo, o racionalismo e a fé na generalização são suas características centrais. Em contrapartida, o pós-modernismo pressupõe que a realidade é algo construído por nossas concepções, as quais são coletivamente sustentadas e permanentemente renegociadas num processo de significação (PARKER, 1992).

Numa perspectiva diferente do entendimento de razão, para o pensamento pós-moderno, a racionalidade está baseada em problematizar questões e não em encontrar respostas. Isso é consistente com a posição genealógica que pressupõe que a fonte da estrutura humana é a disparidade e não a paridade (COOPER e BURRELL, 1988).

Calás e Smircich (1999) enfatizam a importância do pós-modernismo, na medida em que ele transforma a teorização contemporânea, oferecendo uma oportunidade para se refletir sobre a própria produção da teoria.

Para os pós-modernos, a visão de universalidade da verdade não é mais sustentável. A ortodoxia do consenso (metanarrativas) dá lugar às pequenas. Ao se descaracterizar o "conhecimento verdadeiro", torna-se possível o surgimento e a aceitação de "outros conhecimentos", bem como o entendimento das exclusões feitas pelos autores modernistas no sentido de se criar uma textualidade aparentemente neutra (CALÁS e SMIRCICH, 1999; KILDUFF e MEHRA, 1997).

É importante salientar que diversos autores fazem uma distinção entre pós-modernidade, como uma perspectiva teorética, e pós-modernidade, como uma periodização histórica, ou seja, como um período que vem depois da modernidade. Parker (1992) distingue essas duas perspectivas, denominando a primeira de pósmodernidade (sem hífen) e a segunda, como pós-modernidade. Já Thompson (1993), denomina a primeira perspectiva de pós-modernismo, ou seja, uma forma de ver o mundo, enquanto a pós-modernidade está ligada à questão da periodização.

Hassard (1993) procura demonstrar que, como época, o pós-modernismo pressupõe que a sociedade está se movendo para uma nova era (a pós-moderna). Nos estudos organizacionais, a preocupação em relação à perspectiva de uma nova era está ligada à discussão sobre novas formas organizacionais. Como Reed (1993) salienta, desde a década de 1980, estudos comparativos e históricos têm revelado as inadequações e limitações inerentes a uma tese universal das formas organizacionais, bem como da metodologia utilizada, que normalmente se restringe a modelos racionais e sistêmicos.

O modernismo representacional está atrelado a um único conjunto de tendências empíricas ou, como denomina Clegg (1998), ao colete-de-forças da burocracia, que seria, então, o principal mecanismo de conquista da racionalização. Para o autor, o marco da modernidade foi a centralidade da crescente divisão do trabalho ou a diferenciação. Com isso, seu decréscimo, ou processo de "desdiferenciação", pode estar caracterizando uma nova fase, a pós-modernidade. Para Clegg (1998), o fio condutor desse debate está centrado em duas oposições paralelas: a modernidade/pós-modernidade - discutida anteriormente - e a diferenciação/desdiferenciação, aprofundada a seguir.

\section{A burocracia como representação modernista}

A compreensão das diferenças entre novas formas organizacionais e a organização burocrática deve passar por uma revisão de determinados conceitos weberianos. Nesse sentido, é importante ressaltar que a intenção de Weber não era uma análise específica das organizações. Suas preocupações extravasavam a organização em si e estavam centradas no entendimento da relação entre as principais culturas mundiais. Assim, percebe-se uma interpretação seletiva do trabalho de Weber na teoria organizacional (Clegg, 1998).

Para Kalberg (1980), a racionalidade e suas diversas manifestações no processo de racionalização talvez seja o tema principal de Weber. De acordo com o autor, Weber argumentou que o indivíduo não adquire sua "racionalidade" com o século das luzes, pois em todas as épocas passadas, o ser humano foi capaz de ação racional. Os tipos de ação encontram-se "fora da história", ou seja, são traços antropológicos do homem. 
A ação social (incluindo omissão ou tolerância) orienta-se pelo comportamento de outros, seja este passado, presente ou esperado como futuro (...). Os outros podem ser indivíduos e conhecidos ou uma multiplicidade indeterminada de pessoas completamente desconhecidas (Weber, 1991, p.13-14).

São quatro os tipos de ação social: tradicional, afetiva, atrelada a valores e a orientada a fins. A ação social determinada pela tradição constitui o limite da ação social e pode se confundir com o hábito. É caracterizada pela atitude arraigada no cotidiano e, às vezes, não pode ter aplicabilidade no que concerne à "ação com sentido". Assim como a ação tradicional, a ação social determinada pela afetividade, está situada no limite tênue entre a ação com sentido e fora dela.

A ação racional orientada para valores difere das anteriores, no que concerne à elaboração de objetivos e ao planejamento da ação visando à consecução dos primeiros. Porém, tem semelhança com a afetiva, no que se refere ao sentido da ação, pois esta não está centrada nos seus fins ou fora dela, e sim na sua peculiaridade.

Por último, a ação racional orientada para fins se caracteriza pela ponderação e combinação das conseqüências e dos meios para melhor atingir os fins. A decisão entre fins e resultados é conflitante com a ação tradicional e afetiva. Contudo, pode ser determinada pela ação orientada para valores, sendo orientada para fins, apenas, no que se refere à escolha dos meios.

Weber (1991) chama atenção para o fato de que a ação social raramente se orienta por apenas uma dessas maneiras, e que essa classificação também não é exaustiva. Atreladas a essas ações estão os quatro tipos de racionalidade, isto é, a racionalidade formal, teorética, substantiva e a prática.

A racionalidade prática é um julgamento puramente em relação aos interesses individuais, egoísticos e pragmáticos. Refere-se à ação pragmática, em termos de interesse cotidiano. Para Kalberg (1980), a capacidade e a disposição das pessoas para padrões de ação desse tipo permeiam todas as épocas e existem como uma manifestação da capacidade do homem para a ação racional meio-fim.

A racionalidade teorética se caracteriza pela confrontação cognitiva com experiências prévias, ou seja, refere-se ao processo de pensamento como uma lógica dedutiva e indutiva, pois envolve um domínio consciente da realidade, através da construção de conceitos abstratos.

Para Kalberg (1980), tal como a racionalidade prática - ao contrário da racionalidade teorética -, a racionalidade substantiva diretamente ordena ação em padrões. Esse tipo de racionalidade é uma manifestação da capacidade inerente ao homem, para a ação racional de valores. A racionalidade formal legitima um cálculo meio-fim, pela referência a regras ou leis aplicadas universalmente. Para Kalberg (1980), essa orientação para regras e leis equivale à rejeição da arbitrariedade. O autor salienta ainda que diferentemente das demais racionalidades, a formal geralmente se relaciona a uma estrutura de dominação que adquiriu contornos específicos apenas com a industrialização.

A preponderância da racionalidade formal ou instrumental está relacionada à burocratização da sociedade, onde as organizações assumem determinadas características descritas por Weber num tipo ideal. O tipo ideal não é observável na realidade, pois sua intenção é magnificar os traços da realidade, produzindo um conceito hiperconcreto. É exatamente como um tipo ideal que a burocracia constituiu um aparelhamento neutro. Dessa forma, intrinsecamente, ela não é positiva nem negativa. Sua característica é refletir o meio social geral, não sendo emanada de uma essência metafísica (FAORO, 1989; RAMOS, 1983).

Segundo Weber (1963), as características da burocracia são as seguintes:

- as áreas de atuação são ordenadas de acordo com regulamentos (leis ou normas administrativas), onde as atividades são distribuídas de forma fixa;

- prevalece o princípio da autoridade hierárquica; 
- a atividade administrativa se baseia em documentos escritos, que ficam arquivados para posterior verificação;

- pressupõe um treinamento visando à especialização permanente e completa do indivíduo;

- é exigido total envolvimento com as atividades, otimizando a capacidade do trabalhador, a despeito da delimitação do tempo de permanência na organização;

- o desempenho no cargo é norteado por regras escritas e exaustivas que visam prever todas as ocorrências, enquadrando-as dentro de um comportamento definido.

Clegg (1998), citando Perrow, chama a atenção para a defesa da burocracia como um projeto moral. Os princípios da burocracia seriam a expressão de uma racionalidade que daria garantia contra a discriminação. Para o autor, o conceito de racional atrelado à forma de organização "apropriada" à modernidade recebe uma significação precisa, ou seja, procura-se equivaler racionalidade à eficiência.

Os autores neoweberianos, por sua vez, estabeleceram a perspectiva de análise multidimensional, com o objetivo de trabalhar com os atributos burocráticos (divisão do trabalho; hierarquia de autoridade; normas extensivas; separação entre administração, propriedade, salário e promoção, baseados na competência) que, presentes, configuram a forma burocrática de organização (HALL, 1971).Nessa perspectiva, as dimensões da burocracia não estão necessariamente presentes no mesmo grau nas organizações. Estão ordenadas num contínuo e não se apresentam em termos dicotômicos, como presente-ausente. É possível afirmar que os principais alicerces da gestão moderna são a divisão do trabalho e a designação de tarefas e competências, que o indivíduo deveria possuir ou nas quais deveria especializar-se, para seguir carreira ou ascender na hierarquia. Assim, as organizações constituem o veículo onde os processos de diferenciação ocorrem. Para Clegg (1998, p.12) "as organizações tornaram-se os principais palcos destas diferenciações".

Se a modernidade se caracteriza pela diferenciação e por uma teoria moderna, como se caracteriza uma teoria da pós-modernidade nos estudos organizacionais? No livro As organizações modernas, Clegg (1998) delineia uma abordagem centrada no conceito de modos de racionalidade. $\mathrm{O}$ autor destaca que os resultados da pesquisa foram prejudicados, por limitação dos modelos teóricos utilizados, que não possibilitavam retratar a realidade em toda a sua complexidade.

Dessa forma, no próximo tópico, serão apresentados a discussão acerca do conceito de novas formas organizacionais e a proposta de Clegg (1998).

\section{Novas formas organizacionais}

Alguns autores salientam que a transformação da sociedade atual levou ao surgimento de novas formas de atores sociais, que têm pouca relação com o sistema industrial do século passado (PARKER, 1992). Assim, percebe-se uma crescente preocupação com a exploração em torno de conceitos e termos como especialização flexível, pós-fordismo, pós-capitalismo, pós-industrialismo, sociedade da informação, flexibilidade, organização de aprendizagem, dentre outros (DAFT e LEWIN, 1993; VICTOR e STEPHENS, 1994).

As estruturas concebidas para essa nova era são fragmentadas em pequenas unidades de produção e gestão, ligadas pela tecnologia da informação. Essa nova era requer explicação, e nesse sentido, as implicações da perspectiva da periodização da pós-modernidade para a teoria organizacional podem ser resumidas na necessidade de se prover um conjunto prescritivo de estruturas organizacionais, visando a sua sobrevivência e eficiência. Percebe-se nessa perspectiva, a presença dos pressupostos modernistas (PARKER, 1992).

É importante salientar que, embora alguns autores diferenciem a perspectiva de época no que concerne à pósmodernidade como a superação da modernidade, Clegg (1998) defende que não se pode afirmar com clareza que ela foi de fato superada. Os que defendem a sua superação para que se possa observar evidências empíricas de pós-modernidade se baseiam num conceito de tempo linear e evolutivo, distanciando-se dos pressupostos 
desta autora. Embora esta orientação não seja a que norteará este ensaio é importante apresentar os principais autores dessa perspectiva.

Galbraith e Lawler III (1995a) afirmam que as mudanças significativas que estão ocorrendo e ocorreram no ambiente competitivo das organizações provocaram alterações nos hábitos das pessoas e no perfil da força de trabalho, gerando a necessidade de que as organizações - para enfrentarem essa nova realidade - preparem sua estrutura organizacional e seus modelos de gestão. Assim, destacam que "as decisões dos projetos organizacionais devem ser vistas cada vez mais como trocas complexas e decisões contingenciais e não como escolha ditada por modismos" (GALBRAITH e LAWLER III, 1995a, p.XX).

Os autores defendem a idéia de que os arranjos organizacionais são contingentes a circunstâncias do momento, pois consideram que são as forças da competição (custo, qualidade, velocidade de resposta às demandas, poder de compra, tecnologia, dentre outros) que estabelecem as iniciativas estratégicas organizacionais. Nesse contexto de complexidade e variabilidade, perde força a hierarquia encarada até então como forma natural. Como os arranjos organizacionais são contingentes, não existe uma melhor forma de se organizar, sendo múltiplos os arranjos possíveis.

Dentre as novas formas de organização, o autor descreve como emergente o modelo linha de frente/retaguarda. Este é apresentado como um modelo híbrido, ou seja, entre o negócio único e o modelo divisional. Enquanto a linha de frente se associa às questões geográficas e às demandas do consumidor, a retaguarda se relaciona com as questões de matéria-prima, desenvolvimento dos produtos, produção e engenharia. Nesse modelo, todas as ações da corporação vão ao encontro dos consumidores e se caracterizam por atuar em múltiplos locais vendendo um mix de produtos normalmente grande. Galbraith (1995b) salienta que o segredo de seu sucesso está na qualidade dos processos horizontais de integração que ligam a linha de frente com a retaguarda e viceversa.

Galbraith e Lawler III (1995b) resumem algumas características que as organizações devem ter para serem eficientes no futuro próximo. Dentre essas características podemos destacar a descentralização, a organização distribuída, o tamanho da organização, as estruturas não-hierárquicas (ou menos hierárquicas), a fluidez e a configuração transitória. No que concerne à descentralização, os autores ressaltam que as novas configurações (organizações em rede, por equipes, organizações horizontalizadas ou achatadas) pressupõem processos de tomada de decisão mais próximos do cliente. Por sua vez, no que se refere à organização distribuída, à descentralização das atividades anteriormente exercidas pela matriz estas passam a ser executadas por uma divisão ou unidade de negócios, com velocidade e redução de custos.

Quanto ao tamanho, o desafio das organizações passa a ser que, de acordo com as contingências do momento, ela necessita ser grande e pequena ao mesmo tempo. Por fim, consensualmente, é defendida a idéia que as organizações devem reduzir o número de níveis hierárquicos (GALBRAITH e LAWLER III, 1995b).

De modo similar aos autores anteriores, Quinn, Anderson e Finkelstein (2001) defendem que, num ambiente hipercompetitivo, as fontes tradicionais que antes eram dominantes - tais como custos e qualidade, muito dinheiro, know-how e tempo - estão se deteriorando. Para os autores, a única vantagem duradoura é a habilidade de gerar novas vantagens; ou seja, o desenvolvimento e a disseminação do intelecto é que passa a ser "a chave para a sobrevivência na hipercompetitividade" (Quinn, Anderson e Frinkelstein, 2001, p.157). Eles consideram que as novas formas de organização são uma "resposta" ao ambiente, isto é, à globalização da economia, às mudanças tecnológicas e à desregulamentação, dentre outros fatores.

No entanto, no que se refere à burocracia, defendem que as novas formas de organização enraízam-se em estruturas organizacionais maiores que, pelo menos parcialmente, ainda estão burocratizadas. Argumentam que a burocracia não vai, portanto, desaparecer e que a hierarquia, em seu sentido mais amplo, permanecerá como o modo dominante de organizar. $\mathrm{O}$ desafio passa a ser integrar essas várias formas num todo coerente, pois a organização será poliforme e não híbrida. Para os autores, o problema central é que as organizações, para fazerem frente ao ambiente atual, não poderão ser puramente orgânicas, mas precisam combinar as 
propriedades mecânicas com as orgânicas. Destacam que as redes parecem ser capazes de alcançar tanto eficiência (mecânica) quanto flexibilidade (orgânica), superando o clássico dilema mecânico versus orgânico.

Daft e Lewin (1993) defendem a necessidade de uma nova agenda de pesquisa, para que se possa discutir sobre esse novo "paradigma", destacando questões referentes à liderança, ao tamanho, ao alto envolvimento, à organização auto-organizante, à tecnologia da informação, às colaborações organizacionais, aos processos e às transações. Em resumo, os autores argumentam que as características das novas formas organizacionais são:

- hierarquia achatada;

- fronteiras permeáveis (internas e externas);

- tomada de decisão descentralizada;

- grande capacidade para tolerar ambigüidade;

- capacidade de renovação;

- unidades auto-organizantes;

- empowerment dos empregados $\mathrm{e}$

- mecanismos de coordenação auto-integradores.

Em seu estudo sobre novas formas, Grandori (1993) buscou compreender esse conceito, a partir dos mecanismos de coordenação e controle empregados nas trocas internas e externas. Apesar dos formatos organizacionais serem tradicionalmente concebidos como um arranjo interno da organização, atualmente, devem contemplar formas organizacionais que não são somente internas, mas também externas às organizações. Essas formas utilizam mecanismos de coordenação que não são típicos de burocracias mas que, no entanto, são típicos, por exemplo, de mercado, de tecnologia da informação ou de cultura; muitas vezes, descentralizando direitos de decisão e de propriedade. Dentre as formas que usam novos elementos definidores no seu arranjo, a autora destaca: M- formas, $\mathrm{N}$ - formas, P-formas, FS- formas e J-formas.

M-formas são as formas multidivisionais cujo aspecto inovador é a utilização de mecanismos de mercado como coordenador e controlador da ação interna da organização. $\mathrm{N}$-formas são usualmente definidas como organizações em rede, e a coordenação interfirmas se verifica, crescentemente, através de mecanismos como direitos de propriedade. Um outro mecanismo de coordenação utilizado pelas redes é a incidência de informação tecnológica. Quanto às P-formas, existem as parcerias e a participação institucional. Seu mecanismo de coordenação é a democracia. As FS-formas se caracterizam por serem gerenciadas para terem um alto grau de especialização e, conjuntamente, um alto grau de flexibilidade. Por fim, as J-formas se referem à utilização de mecanismos normativos de coordenação e controle.

As inovações radicais apresentadas por Grandori (1993) são os diferentes mecanismos de coordenação. São esses novos elementos ou dimensões de organização que tornam o conceito tradicional de forma inadequado pois, normalmente, esta tem sido concebida como um arranjo interno, definido a partir do tipo e da intensidade de divisão do trabalho, pelo tipo de distribuição de poder e de decisão, como também pelo tipo e a intensidade dos mecanismos de coordenação empregados.

No que se refere aos diferentes modos de ligação entre os componentes organizacionais ou propriedades de ligação, a autora destaca o preço, o contrato, a autoridade, as regras formais, os procedimentos, as normas sociais, a padronização, a informação e as tecnologias de comunicação. Embora, esses modos de ligação estejam presentes na literatura sobre desenho organizacional, não é usual a definição das características básicas da estrutura a partir da alocação de direitos. Para Grandori (1993), essa é uma conseqüência lógica de não se conceber a organização como um sistema natural ou um "objeto", mas como um "jogo" onde múltiplos atores são potencialmente conflitantes. Os mecanismos de coordenação - divididos em propriedades de nódulos e propriedades de ligações - possuem diferentes naturezas e funções, sendo que as novas formas de organização combinam esses elementos de maneira inovativa. 
Romanelli (1991) faz uma revisão da literatura que procura explicar a natureza dos contextos e processos que podem gerar novas formas organizacionais. Segundo a autora, três perspectivas agrupam a maioria dos argumentos, são elas: a visão genética organizacional, a visão da condição ambiental e a visão dos sistemas sociais emergentes.

A autora enfatiza a importância de se ter uma linha básica para comparar novas formas organizacionais e afirma que:

"Evolução pode apenas ser conhecida depois do fato, quando diferenças na forma podem ser claramente identificadas. (....) O conceito de forma organizacional ajuda a clarear o ponto em que evolução é o estudo de mudanças nos tipos, não mudanças em entidades individuais. $\mathrm{O}$ processo pelo qual diferenças evolucionárias emergem torna-se aberto para as discussões" (ROMANELLI, 1991, p.84) (grifo nosso).

Dessa forma, a autora parece relacionar novas formas organizacionais a uma perspectiva linear e evolutiva. Assim como Burrell (1993), a autora concebe o tempo como uma espiral infinita. Considera que essa noção de tempo possibilita um melhor entendimento dos códigos de tempo heterogêneos, os quais definem os contornos da mudança organizacional em curso.

Para Romanelli (1991), é apropriado fazer uma revisão das perspectivas sobre evolução das formas organizacionais, a partir da própria pesquisa que trata diretamente dessa questão, ou seja, a visão genética organizacional que se baseia nos modelos biológicos evolucionários. Como representantes dessa perspectiva, cita o livro de McKelvey e o de Nelson e Winter, - ambos publicados em 1982 -que abordam de modo diferente a questão, mas que se baseiam na analogia biológica para analisar a variação nas formas organizacionais.

A despeito da diferença de abordagem, McKelvey, Nelson e Winter entendem que as mudanças nas condições ambientais podem aumentar ou diminuir a taxa de variação que ocorre na comunidade organizacional. Contudo, salientam que não é a mudança no ambiente que vai ditar a ocorrência de variações particulares, já que as variações nas atividades organizacionais podem ser oriundas ou condicionadas pela natureza das rotinas. As teorias genéticas limitam seu foco ao processo de evolução, não às suas consequiências específicas.

Assim, Romanelli (1991) salienta que enquanto a perspectiva anterior focava nos processos a nível micro, a visão de condicionamento ambiental se preocupa em analisar como as condições do ambiente podem produzir variações nas formas organizacionais. Dessa forma, consideram que o ambiente afeta as variações das formas organizacionais e restringem os tipos de variações que podem ser criadas.

A terceira perspectiva apresentada pela autora é a dos sistemas sociais emergentes. Seus representantes são Van de Ven \& Garud e Rappa. Eles pressupõem que as variações nas formas organizacionais são produtos do imbricamento das interações sócioorganizacionais.

Romanelli (1991) destaca que três áreas tradicionais do pensamento sobre evolução organizacional não foram apresentadas, dentre elas cita a que aborda o ciclo de vida das organizações. Dentre as suas justificativas para a retirada dessa abordagem, afirma que "nada nessas teorias, entretanto, sugere que evolução será sinônimo de progresso ou avanço". Dessa forma, fica clara a posição da autora quanto a sua visão de novas formas como algo que leva ao progresso e ao avanço social e econômico.

Apesar dos esforços realizados tanto por Grandori como por Daft e Lewin, os autores salientavam ainda a necessidade de novas explicações e abordagens para o estudo de novas formas. Para Grandori (1993), quase todas as teorias sobre desenho organizacional não fornecem ferramentas para uma análise mais adequada. Já Daft e Lewin (1993) destacam a necessidade de uma nova agenda de pesquisa e afirmam a importância de se desenvolver uma nova abordagem para pesquisa sobre novas formas.

Clegg (1998) é um dos autores que demonstra a inadequação de diversas abordagens. O autor salienta que algumas teorias, dentre elas a perspectiva da ecologia da população, tendem a compreender o ambiente como 
fonte de incertezas e negligenciam a desordem inerente às questões organizacionais. Para o autor, esse determinismo teórico só é possível na medida em que se nega os elementos organizacionais relacionados à "agência". Entretanto, em contrapartida, muitos estudos demonstram que as organizações podem determinar características importantes dos seus ambientes.

Assim, certas configurações organizacionais não podem ser explicadas através do pressuposto de que são uma simples resposta às pressões da eficiência e da eficácia. Entretanto, isso não significa negar sua influência, mas significa afirmar que a sua resposta é muito mais complexa do que a apresentada por abordagens que analisam somente esse aspecto.

A definição de eficiência econômica não ocorre num vácuo social, mas é dependente de uma contextualização social. A existência de contextos sociais diferentes e a diversidade de quadros institucionais conduzirão a "modos de racionalidade" diferenciados (GRANOVETTER, 1985; CLEGG, 1998). Para Clegg (1998), os modos de racionalidade são construídos pelos atores estratégicos e incluem as práticas legitimadas no ambiente de ação. Como se pode observar, o conceito de eficiência é mediado pelos atores dominantes, e as diferentes concepções de eficiência influenciam as formas e os meios através dos quais os mesmos tentam reproduzir a sua dominação.

Para se compreender a proposta analítica do autor é necessário salientar algumas observações. Primeiro, Clegg utiliza os exemplos de produção do pão francês, a produção de moda da Benetton e as empresas asiáticas para demonstrar que essa diversidade não é passível de explicação a partir das abordagens centradas no mercado. Segundo, refuta as tentativas de explicação dessa diversidade a partir de um reducionismo cultural e, por fim, defende a idéia de que as formas organizacionais, como dito anteriormente, são uma construção humana estruturada pelas agências através das racionalidades discursivas, que se diferenciam em função da sua localização institucional.

Ao se ter essa perspectiva - no que concerne à forma organizacional -, percebe-se que certas características que podem ser julgadas inadequadas ou como fraquezas, aos olhos de um estranho, se vistas por um outro olhar, são de fato um ponto forte. Clegg (1998), se diferencia da literatura dominante sobre forma, ao entender que existe uma articulação específica de contingências, tais como as associadas às características organizacionais, aos mercados, ao Estado e à cultura, as quais apresentam um peso explicativo diferenciado nos diversos países. Dessa forma, entende que as práticas locais são as principais contingências que podem agir tanto como fatores de resistência quanto facilitadores das pressões de mercado, da ecologia ou institucional. A maneira de agir depende dos modos de racionalidade, construídos a partir das agências localizadas tanto no interior das organizações quanto em torno delas, como também depende de qual recurso foi o mais utilizado nessa construção.

Portanto, é possível afirmar que tal negócio em determinado país é mais ou menos racional do que outro? É possível afirmar que o produto X é um "produto" irracional? Para o autor que parte do entendimento de que as racionalidades são construídas pelos próprios agentes e que são as práticas locais que moldam sua construção e reprodução, a resposta a essas questões, certamente, é negativa. Acredita-se, dessa forma, na limitação das teses universalistas que defendem a eficácia como elemento explicativo de um limitado número de formas organizacionais (CLEGG, 1998).

Uma outra diferenciação da proposta de Clegg é que ele não associa o pós-modernismo e as suas formas decorrentes como vazias de significado político, bem como não defende nenhum contorno da pós-modernidade como tendo um caráter inevitável. É a partir dos pressupostos analíticos do autor, apresentados anteriormente, que se pode compreender a sua proposta. Nesse sentido, críticas como a de Thompson (1993), que compara Clegg aos gurus da administração, é demasiadamente forte, tendo em vista que ele não prega nenhuma solução e muito menos receitas a serem aplicadas para solucionar problemas com agilidade.

Para Clegg (1998), a diferença entre uma organização modernista e uma supostamente pós-modernista não pode ser estabelecida somente a partir de elementos baseados na competência, mas deve ser ampliada para abarcar dimensões e elementos relativos à formação de capital e à forma como ambos possibilitam diferentes 
ações organizacionais, em função de modos de racionalidade diversos. Com base em Blunt, ele seleciona sete imperativos organizacionais:

- a articulação da missão, das metas, das estratégias e das principais funções;

- o estabelecimento de relações funcionais;

- a identificação dos mecanismos de coordenação e de controle;

- a promoção da responsabilização e das relações entre papéis;

- a institucionalização do planejamento e da comunicação;

- o relacionamento entre recompensas e desempenho; e

- alcance de uma liderança eficaz.

Para o autor, deve-se analisar os padrões coerentes que esses imperativos organizacionais formam e não os desvios em relação à norma. Assim, afirma:

"Contra qualquer forma de determinismo poderá querer defender-se que, pelo contrário, as contingências e as instituições devem ser encaradas como arenas onde os que disputam o poder tentarão utilizar todos os recursos disponíveis para a construção de uma prática organizacional local, que será moldada por um qualquer modo de racionalidade, em termos contrários ao último dos imperativos organizacionais" (CLEGG, 1998, p.242).

O autor procura demonstrar que é possível a emergência de um modo de racionalidade diferente e que, pela sua oposição aos princípios do modelo burocrático, expressam um modo de racionalidade pós-modernista. Entretanto, a explicação dessa emergência não se centra nem numa abordagem mercadológica (subsocializada) nem culturalista (sobressocializada).

\section{Considerações finais}

Este artigo buscou demonstrar a necessidade de superar as abordagens dominantes na teoria organizacional sobre novas formas organizacionais. Primeiramente, defendeu-se uma ruptura com a epistemologia que permeia o projeto modernista, cuja caraterística é adotar um referencial de análise centrado na explicação das "causalidades". Com isso não se defendeu a existência de características universais da realidade, mas a existência simultânea de realidades diversas. Defendeu-se também que a existência de uma nova forma independe da "morte da burocracia".

Quanto à existência de novas formas como resposta direta às pressões ambientais, mostrou-se que essa perspectiva dominante conduz à uma explicação subsocializada e, por esse motivo, irreal. Ela desconsidera a imersão da organização num ambiente permeado por relações sociais, políticas e culturais.

Por outro lado, a concepção de que as novas formas são uma evolução em relação à outras vai de encontro ao pressuposto adotado aqui quanto à concepção de tempo. Neste trabalho, o tempo foi entendido como uma espiral que possibilita a vivência simultânea de diferentes formas organizacionais, sem o intuito de colocá-las numa ordem evolutiva e linear.

Ontologicamente, defendeu-se que o mundo social é construído pelos seus diversos atores em um processo constantemente negociado, não existindo, assim, uma forma "correta" ou "verdadeira" de se descrever esse mundo. Assim, as metodologias normalmente utilizadas para compreender a forma organizacional, quando atreladas a modelos racionais e sistêmicos, tornam-se inadequadas, pois buscam uma tese universal para explicá-las.

Ao se pressupor a universalidade, a causalidade e ao se adotar metodologias positivistas, os autores não se permitem perceber a existência de outros modos de racionalidade. Dellagnelo (2000), ao procurar identificar as evidências empíricas da superação da racionalidade instrumental em artigos nos principais periódicos 
nacionais/internacionais, constatou que a racionalidade predominante é a instrumental, não sendo possível observar outras lógicas de ação.

É importante destacar que o fato de não ter sido possível observar outras lógicas de ação não significa que elas não existam. Ou seja, considerando que os autores daqueles artigos não tivessem como pressuposto a possibilidade de existência de outros modos de racionalidade, certamente, eles não perceberiam. Isto é, são os pressupostos epistemológicos e ontológicos do autor que permitem o surgimento ou não de diferentes narrativas.

Em consonância com Dellagnelo (2000), destaca-se como fundamental a consideração do tipo de racionalidade subjacente, para que se supere a fragilidade teórica que permeia a literatura gerencialista. Nesse sentido, o trabalho da autora serve como um importante alerta, pois não se pode esquecer que a ação administrativa é uma ação social (RAMOS, 1983) e, portanto, raramente ela vai se orientar por uma única racionalidade (Weber, 1991).

As pesquisas, ao enfocarem somente a organização em si, não permitem a observação das relações que permeiam essa organização e que a constituem, delineando sua forma organizacional e as suas lógicas de ação. Assim, ao se analisar os elementos constituintes da forma organizacional, não se deve buscar compará-los com uma tipologia, verificando em que medida esses elementos se desviam ou não; mas se deve procurar compreender qual a lógica que perpassa a configuração de tais elementos. Como o contexto cultural, político e econômico pode explicar tal configuração? Como as concepções compartilhadas interferem na estruturação das relações estabelecidas por essa organização?

Portanto, é necessário compreender o imbricamento da organização com uma estrutura social mais ampla. Dessa forma, é possível trabalhar simultaneamente com os aspectos macroeconômicos, culturais e societais sem desconsiderar as variáveis organizacionais (por exemplo: os limites cognitivos dos dirigentes e seus esquemas interpretativos, a cultura organizacional) que possibilitam a produção de diferentes formas organizacionais, embora dentro do mesmo contexto. 


\section{Referências bibliográficas}

ALVESSON, M.; DEETZ, S. Teoria crítica e abordagens pós-modernas para estudos organizacionais. In: CLEGG, S.; HARDY, C.; NORD, W. Handbook de estudos organizacionais. São Paulo: Atlas, 1998. v.1.

BURRELL, G.; MORGAN, G. Sociological paradigms and organizational analysis. London: Heinemann, 1979.

CALÁS, M. B.; SMIRCICH, L. Postmodernism? Reflections and tentative directions. Academy of Management Review, v.24, n.4, p.649-671, 1999.

CARTER, P.; JACKSON, N. Modernism, postmodernism and motivation, or why expectancy theory failed to come up to expectation. In: HASSARD, J.; PARKER, M. Postmodernism and organizations. London: Sage Publications, 1993.

CLEGG, S. R. As organizações modernas. Oeiras: Celta Editora, 1998.

; HARDY, C. Introdução: organização e estudos organizacionais. In: CLEGG, S.; HARDY, C.; NORD, W. Handbook de estudos organizacionais. São Paulo: Atlas, 1998. v.1.

COOPER, R.; BURRELL, G. Modernism, postmodernism and organizational analysis: an introduction. Organization Studies, v.9, n.1, p.91$112,1988$.

DAFT, R. L.; LEWIN, A Y. Where are the theories for the "new" organizational forms? Organization Science, v.4, n.4, p.I - VII, 1993.

DELLAGNELO, E. H. L. Novas formas organizacionais: ruptura com o modelo burocrático? 2000 (Tese de doutorado) Florianópolis.

FAORO, R. Os donos do poder: formação do patronato político brasileiro. Rio de Janeiro: Globo, 1989. v.2.

GALBRAITH, J. A corporação que agrega valor: combinando estrutura e estratégia. In: GALBRAITH, J., et al. Organizando para competir no futuro: estratégia para gerenciar o futuro das organizações. São Paulo, Makron Books, 1995a.

. A unidade de negócios do futuro. In: GALBRAITH, J. et al. Organizando para competir no futuro: estratégia para gerenciar o futuro das organizações. São Paulo, Makron Books, 1995b.

, LAWLER III, E. E. Introdução - desafios à ordem estabelecida. In: GALBRAITH, J. et al. Organizando para competir no futuro: estratégia para gerenciar o futuro das organizações. São Paulo, Makron Books, 1995 a.

Organizações eficientes: usando a nova lógica da organização. In: GALBRAITH, J. et al. Organizando para competir no futuro: estratégia para gerenciar o futuro das organizações. São Paulo, Makron Books, 1995b.

GRANDORI, A. Inventing effective organization forms. 1993. Trabalho apresentado no $11^{\text {th }}$ Egos Colloquim - European Group for Organization Studies. The production and difusion of managerial and organizations knowledge. Paris, 1993.

GRANOVETIER, M. Economic action and social structure: the problem of embeddedness. AJS, v.91, n.3, nov. 1985.

HALL, R. H. O conceito de burocracia: uma contribuição empírica. In: CAMPOS, E. Sociologia da burocracia. Rio de Janeiro: Zahar Editores, 1971.

HASSARD, J. Postmodernism and organizational analysis: an overview. In: HASSARD, J.; PARKER, M. Postmodernism and organizations. London: Sage Publications, 1993.

HEYDEBRAND, W. V. New organizational forms. Work and Occupations, v.16, n.3, p.323-357, Aug. 1989.

HORCKEIM ER, M.; ADORNO, T. W. Dialética do esclarecimento: fragmentos filosóficos. Rio de Janeiro: Jorge Zahar Ed., 1985.

KALBERG, S. Max Weber's types of rationality: cornestones for the analysis of rationalization processes in History. AJS, Chicago, v.85, n.5, p.1145-1179, 1980.

KILDUFF, M.; MEHRA, A. Postmodernism and organizational research. Academy of Management Review, v.22, n.2, p.453- $481,1997$.

MOHRM AN Jr., A. M.; LAWLER III, E. E. Administração de recursos humanos: construindo uma parceria estratégica. In: GALBRAITH, J. et al. Organizando para competir no futuro: estratégia para gerenciar o futuro das organizações. São Paulo, Makron Books, 1995.

MCCALL Jr., M. W. Desenvolvendo liderança. In: GALBRAITH, J. et al. Organizando para competir no futuro: estratégia para gerenciar o futuro das organizações. São Paulo, Makron Books, 1995.

QUINN, J. B.; ANDERSON, P.; FINKELSTEIN, S. Novas formas de organização. In: MINTZBERG, H.; QUINN, J. B. 0 processo da estratégia. 3. ed. Porto Alegre: Bookman, 2001.

RAM OS, A. G. Administração e estratégia do desenvolvimento. Rio de Janeiro: Editora FGV, 1983.

A nova ciência das organizações. Rio de Janeiro: Editora. FGV, 1989.

REED, M. Introduction. In: REED, M; HUGHES. Rethinking organization: new directions in organization theory and analysis. London: Sage Publications, 1993. 
Teorização organizacional: um campo historicamente contestado. In: CLEGG, S.; HARDY, C.; NORD, W. Handbook de estudos organizacionais. São Paulo: Atlas, 1998. v.1.

ROMANELL, E. The evolution of new organizational forms. Annual Review of Sociology, v.17, p.79- 103, 1991.

THOM PSON, P. Postmodernism: fatal distraction. In: HASSARD, J.; PARKER, M. Postmodernism and organizations. London: Sage Publications, 1993.

VICTOR, B.; STEPHENS, C. The dark side of the new organizational forms: an editorial essay. Organization Science, v.5, n.4, p.479-482, nov.1994.

WEBER, M. Ensaios de Sociologia. Rio de Janeiro: Zahar Editores, 1963.

. Economia e Sociedade. Brasília, Ed. UNB, 1991. v.1. 